\title{
Sobre a Crítica do Conhecimento de Walter Benjamin
}

\author{
Mateus Gonçalves de Medeiros*
}

Resumo

A diferenciação entre saber e verdade em Questões Introdutórias de Crítica do Conhecimento, prefácio da obra Origem do Drama Barroco Alemão de Walter Benjamin, mostra que o primeiro pode ser possuído na consciência enquanto a verdade esquiva-se a qualquer tentativa de apropriação. Apenas o saber responde a uma questão de caráter intencional. Enquanto Ser indefinível, a verdade não entra em nenhum tipo de relação. Ela se auto-representa. Na ordem do fenômeno, "reino do particular", pode-se vislumbrar a essência da verdade de forma fugaz como um relâmpago. Essa reflexão repercute no modo como o autor pensa uma filosofia da história. Benjamin nega a possibilidade de apoderar-se do fato histórico. $O$ conhecimento causal e linear do historicismo não apresenta a história em seu movimento universal, mas apenas o ponto de vista de quem venceu - ideologia que expressa a intenção de quem está no poder. A proposta de Walter Benjamin articula o ocorrido com o agora (Jetztzeit), ao perceber no que é hodierno, o fragmento do que passou. Esse mesmo caráter de linearidade criticado na historiografia caracteriza o more geometrico presente na metodologia das ciências humanas. A noção de sistema, com sua pretensão universalizante, é criticada por Benjamin na medida em que o ato de tecer uma linha contínua e fechada de argumentos não é suficiente para dar conta da realidade. O método da representação encontra, no mosaico, a alternativa para valorizar a unidade do singular, e na contemplação do tratado, o fôlego infatigável que caracteriza o movimento do pensamento. Essa metodologia evita a intencionalidade do modo causal de investigação, no sistema. Como exemplo do desvio do caráter intencional temos a alegoria, a obra de arte e a experiência. Cada uma delas esquiva-se da ideologia, salvando o particular para a totalidade.

Palavras-chave: Verdade, saber, Ética, Gnoseologia, Walter Benjamin, Trauerspiel.

* Mateus Gonçalves de Medeiros é Mestre em Filosofia pela UECE 
Abstract

The distinction between knowledge and truth in Introductory Questions of Knowledge Critique, preface of the work Origin of German Tragic Drama, shows that the former can be owned in the conscience whereas the latter hedges any attempt of appropriation. Only knowledge answers an intentional question. While indefinable being, the truth does not enter in any sort of relationship. It represents itself. As a phenomenon, 'in the realm of privacy', it is possible to perceive the essence of truth as brief as a streak of lightning. This reflection has an influence on how the author reckons the Philosophy of History. Benjamin denies the possibility of taking hold of the historical fact. Causal and linear knowledge of historicism does not present history in its universal movement, it merely presents the point of view of winners- ideology which expresses the intention of who is in power. The proposal of Walter Benjamin articulates the happened with the now (Jetztzeit), by noticing in what is current, the fragment of what is gone. This same linear nature criticized in Historiography characterizes the more geometrico present in the Human Science methodology. The idea of system, in its universalizing intention, is criticized by Benjamin as far as the act of producing a continuous and closed chain of arguments concern is not enough to cope with reality. The method of representation finds in the mosaic, the alternative to appreciate the unity of singularity, and in the contemplation of the treaty, the unremitting breath which characterizes the movement of thought. This methodology avoids the intentionality of causal mode of investigation in the system. As an example of the intentional nature deflection, we have the allegory, the work of art and the experience. Each one of them hedges from ideology, saving the private for the entirety.

Keywords: Truth; Knowledge; Ethics; Gnoseology; Walter Benjamin; Trauerspiel 


\title{
Sobre a Crítica do Conhecimento de Walter Benjamin
}

\author{
Enquanto o conceito emerge da \\ espontaneidade do entendimento, as idéias \\ se oferecem à contemplação ${ }^{l}$
}

Em Questões Introdutórias de Crítica do Conhecimento, Walter Benjamin estabelece a diferença entre o conceito de saber e o conceito de verdade. O primeiro pode ser possuído pelo indivíduo. O segundo escapa a qualquer tentativa de apropriação. Por isso, logo no início de seu texto, o autor faz alusão ao pensamento de Platão, que propôs a tese de que "o objeto do saber não coincide com a verdade"2. Esta tese, "revela-se, sempre de novo, uma das mais profundas intuições da filosofia original, a doutrina platônica das idéias"3. Aqui, nos deparamos com o ser indefinível da verdade. Apenas o conhecimento pode ser questionado. E somente ele pode ser possuído. "A especificidade do objeto do saber é que se trata de um objeto que precisa ser apropriado na consciência, ainda que seja uma consciência transcendental. Seu caráter de posse lhe é imanente" ${ }^{4}$. Para Walter Benjamin, é da própria natureza do objeto do saber o fato de que ele é apropriado, apoderado pelo indivíduo. Mais do que um aspecto curioso, a apropriação do objeto na mente da criatura é necessária para que o saber aconteça. Com o intuito de corroborar essa declaração, Benjamin brinca ao dizer que o saber é apoderado pela consciência mesmo se esta for transcendental, em uma referência a Immanuel Kant. Mesmo para o objeto de uma consciência não-empírica, todo o saber que o "eu penso" tomar como objeto, será por ele apropriado. A própria expressão "tomar como objeto", comumente usada na língua portuguesa, explicita o caráter de posse do saber.

Com relação à verdade, o discurso é oposto. A verdade não pode ser possuída por qualquer que seja a consciência. No momento em que intencionamos nos apoderar da verdade, ela escorre por entre os nossos dedos. E se algo sobra em nossas mãos, é apenas saber. A verdade não pode ser dominada. Apenas o saber pode sê-lo.

\footnotetext{
${ }^{1}$ BENJAMIN, Walter. Origem do drama barroco alemão. Trad. Sergio Paulo Rouanet. São Paulo, Brasiliense, 1984. P.52.

2 Ibidem. P. 52.

${ }^{3}$ Ibidem. P. 52.

${ }^{4}$ Ibidem. P. 51.
} 
"O saber visa o particular, mas não a unidade desse particular" 5 ". A afirmação de Walter Benjamin põe o conhecimento científico em seu devido lugar. A empiria tem como objetivo conhecer o particular, mas não é capaz de vislumbrar a relação entre esse particular e o todo, assim como uma peça do mosaico medieval se relaciona com cada uma das outras de forma individual, mas também com a totalidade do artefato. A essência da verdade, presente no particular, ou seja, na "unidade do singular", também está presente em cada um dos fragmentos do mosaico do real. Mas essa essência escapa ao saber, que não pode se relacionar com a verdade de uma forma direta. Ele é mediado pelo conceito. "A unidade do saber, se é que ela existe, consiste apenas numa coerência mediata, produzida pelos conhecimentos parciais e de certa forma por seu equilíbrio, ao passo que na essência da verdade a unidade é uma determinação direta e imediata ${ }^{6}$ ". O saber não pode atingir a verdade uma vez que ele alcança apenas o patamar do conceito. Não é possível ao saber questionar diretamente a verdade, em uma relação imediata. “Como unidade no Ser, e não como unidade no Conceito, a verdade resiste a qualquer interrogação" ${ }^{7 "}$.

"A verdade é a morte da intenção" menos em uma relação intencional. "A verdade é um ser não intencional formado de idéias (Die wahrheit ist ein aus Ideen gebildetes intentionsloses Sein ${ }^{9}$ )". Apenas o objeto do saber pode ser determinado. Essa é a razão porque o saber não pode dizer a verdade. Aquele é repleto da intencionalidade. Como o saber é fruto de uma individualidade, o conhecimento que emana desse saber estará repleto das particularidades de quem o pensou. As próprias intenções do indivíduo estarão expressas na forma final de um saber. Portanto, não se pode afirmar que o saber coincide com a verdade, pois isto a reduziria a um grupo de conceitos que teriam muito mais a ver com o ponto de vista de um ou de outros.

A intencionalidade também se revela na comunicação. Esta, visando a mera transmissão de informação, relaciona-se com a persuasão que busca o convencimento do outro sobre

\footnotetext{
${ }^{5}$ BENJAMIN, Walter. Origem do drama barroco alemão. Trad. Sergio Paulo Rouanet. São Paulo, Brasiliense, 1984. P.52.

${ }^{6}$ Ibidem. P. 52.

${ }^{7}$ Ibidem. P. 52.

${ }^{8}$ BENJAMIN, Walter. Origem do drama barroco alemão. Trad. Sergio Paulo Rouanet. São Paulo, Brasiliense, 1984. P. 58.

${ }^{9}$ BENJAMIN, Walter. Ursprung des Deutschen Trauerspiels. Frankfurt Am Main, Suhrkamp Verlag, 1998. P. 18.
} 
um determinado saber. Mas "convencer é infrutífero", transmitida de um indivíduo para outro. A verdade apenas pode ser experienciada pela criatura, que não possui meios de transmitir sua experiência a alguém. A experiência da verdade, que se revela de maneira fugaz, é apenas daquele que vislumbrou a sua autoapresentação. Por isso a analogia que Benjamin faz da mônada de Leibniz. Esta não tem janelas $^{11}$, o que significa dizer que ela não precisa estabelecer qualquer tipo de comunicação com as demais mônadas, pois todas, apesar de diferentes, possuem a mesma essência. Cada uma delas possui dentro de si todas as possibilidades relativas à sua existência. O significado da analogia que Benjamin vislumbra na mônada é que nela existe a possibilidade instantânea de revelação da verdade. Esta experiência de revelação não é transmitida através da comunicação. A experimentação da verdade, estando longe de ser um apoderamento da idéia platônica, não pode ser transmitida, uma vez que não se pode transmitir o que não se possui. Por isso, a verdade, em sua objetividade pura, não pode ser alcançada pelo saber densamente carregado de intenções. Como exemplo desse caráter de intencionalidade do saber, podemos citar o conceito de empatia.

Essa fatídica sugestibilidade psicológica, pela qual o historiador, por um processo de substituição, procura colocar-se no lugar do criador, como se este, por ter criado a obra, fosse também o seu melhor intérprete, recebeu o nome de empatia, que mascara a simples curiosidade com o disfarce do método ${ }^{12}$.

O historiador não pode possuir a verdade do fato histórico. A própria escolha do fato a ser estudado já é uma seleção repleta de intenções pela empatia que este historiador estabelece com o seu objeto. Assim, Walter Benjamin se posiciona contra a orientação positivista que visa alcançar nas ciências humanas a mesma neutralidade encontrada nas ciências naturais. É próprio do conhecimento que ele estabeleça uma relação intencional com o seu objeto, não sendo possível a imparcialidade absoluta tanto desejada.

\footnotetext{
${ }^{10}$ BENJAMIN, Walter. Rua de Mão Única. Obras Escolhidas. Volume 2. Tradução de Rubens Rodrigues Torres Filho e José Carlos Martins Barbosa. São Paulo, Brasiliense, 1987. P. 14.

11 “As Mônadas não têm janelas, pelas quais alguma coisa nelas possa entrar ou delas sair. Os acidentes não poderiam desligar-se, nem passear-se fora das substâncias, como faziam outrora as espécies sensíveis dos Escolásticos. Assim, nem substância nem acidente pode entrar de fora numa Mónada". LEIBNIZ, G. W. Princípios da Natureza e da Graça - Monadologia. Tradução de Miguel Serras Pereira. Lisboa, Fim de Século, 2001. P. 42.

${ }^{12}$ BENJAMIN, Walter. Origem do drama barroco alemão. Trad. Sergio Paulo Rouanet. São Paulo, Brasiliense, 1984. P. 76.
} 
A pergunta "como de fato aconteceu?" não pode sequer ser colocada. Somente com essa ponderação (...) será possível decidir se a idéia é uma abreviação indesejável ou o fundamento do verdadeiro conteúdo científico, em sua expressão lingüística ${ }^{13}$.

Diz ainda Benjamin na tese 7 de seu texto "Sobre o Conceito da História":

Fustel de Coulanges recomenda ao historiador interessado em ressuscitar uma época que esqueça tudo o que sabe sobre fases posteriores da história. Impossível caracterizar melhor o método com o qual rompeu o materialismo histórico. Esse método é o da empatia. Sua origem é a inércia do coração, a acedia, que desespera de apropriar-se da verdadeira imagem histórica, em seu relampejar fugaz ${ }^{14}$.

Atingir a acedia, a inércia absoluta do coração, ou seja, a ausência de paixões, de afetos, é uma tarefa impossível para o ser humano. Realizar a inércia do coração é negar a própria essência do ser humano. Sendo impossível alcançar esse estado de pura imparcialidade, da mesma forma é impossível que o ser humano possa realizar o sonho de apropriar-se da verdadeira imagem histórica. O "relampejar fugaz" não pode ser apropriado pelo homem simplesmente porque ele decidiu ser inalcançável às paixões. $\mathrm{E}$ ainda, o exercício de esquecer ou ignorar todo o conhecimento sobre a história posterior ao tempo estudado não faz sentido dentro do pensamento benjaminiano uma vez que, para ele, um evento histórico tem de ser visto a partir da janela do presente. Ele deve fazer sentido no presente que, por isso, se sente atraído por um acontecimento passado. Este último atualiza-se, presentifica-se, ganhando uma significação atual. "Pois irrecuperável é cada imagem do passado que se dirige ao presente, sem que esse presente se sinta visado por ela ${ }^{15}$.

Ainda sobre a tese 7, diz Benjamin:

Para os teólogos medievais, a acedia era o primeiro fundamento da tristeza. Flaubert, que a conhecia, escreveu: "Peu de gens devineront combien il a fallu être triste pour ressusciter Carthage". A natureza dessa tristeza se tomará mais clara se nos perguntarmos com quem o investigador historicista estabelece uma relação de empatia. A resposta é inequívoca: com o vencedor. Ora, os que num momento dado dominam são os herdeiros de todos os que venceram antes. A empatia com o vencedor beneficia sempre, portanto, esses dominadores ${ }^{16}$.

A questão da empatia, que é o mesmo problema da intencionalidade do conhecimento, é que o conceito não pode dar conta da imagem da verdade. Assim, a história tradicional acabou por tender a interpretar através do ponto de vista de quem a escreveu, no caso,

\footnotetext{
13 Ibidem, p. 64.

${ }^{14}$ BENJAMIN, Walter. Sobre o Conceito da História. In: Magia, Técnica, Arte e Política: ensaios sobre literatura e história da cultura. Obras Escolhidas. Volume 1. Tradução: Sergio Paulo Rouanet. São Paulo, Brasiliense, 1985. P. 225.

15 Ibidem. P. 224.

16 Ibidem. P. 225.
} 
os "vencedores". Acreditar que o viés historicista coincide com o universal histórico é ignorar a multiplicidade de pontos de vista possíveis sobre o passado. Aceitar o outro (ou os outros) da história significa romper a cadeia única de acontecimentos que beneficia os herdeiros dos herdeiros dos vencedores. Acolher o heterogêneo é negar que a história rume para um único fim conhecido, é negar a idéia conformista de que os dominadores sempre estarão no posto do vencedor. Assumir a diferença, parafraseando Giorgio Agamben, é profanar o improfanável. Uma vez que, segundo Agamben, o termo profanar, em seu sentido etimológico, significava restituir algo ao livre uso dos homens ${ }^{17}$, algo que antes permanecia em estado de consagração, pode-se afirmar que recusar dogmas pré-estabelecidos ou mesmo recusar o manto da autoridade sob o qual alguns ainda se escondem, é restituir a heterogeneidade ao seu posto merecido. Em um momento onde não é mais cabível uma argumentação que se baseie no princípio de uma verdade possuída por um indivíduo, o outro, a diferença, o heterogêneo, reconquista sua posição de destaque.

Posta a distinção entre a verdade e o saber, não podemos mais pensar que o conceito, produzido pelo conhecimento, pode coincidir com a verdade. Não podemos possuir sua essência, mas resta-nos ainda uma alternativa: o caminho da representação.

\section{A crítica do método científico e a proposta da representação da verdade}

A discussão que Walter Benjamin faz sobre a verdade e o saber traz como consequiência, a crítica do método científico. Para o autor, o more geometrico da matemática nos demonstra que para chegarmos ao conhecimento genuíno, devemos eliminar totalmente qualquer forma de representação. No momento em que a ciência busca a eliminação de qualquer tipo de representação (Darstellung), "ela renuncia à esfera da verdade que é visada pela linguagem"18. E é nesta mesma esfera da verdade em que a linguagem se situa, onde se dá a verdadeira forma da filosofia: a apresentação da verdade capaz de codificar a história. A questão é que, se não é possível nos apropriarmos da verdade, como foi discutido na reflexão anterior, a representação das

\footnotetext{
17 "E se consagrar (sacrare) era o termo que designava a saída das coisas da esfera do direito humano, profanar, por sua vez, significava restituí-las ao livre uso dos homens. 'Profano' - podia escrever o grande jurista Trebácio - 'em sentido próprio denomina-se àquilo que, de sagrado ou religioso que era, é devolvido ao uso e à propriedade dos homens'”. AGAMBEN, Giorgio. Profanações. Trad. Selvino J. Assmann. São Paulo: Boitempo, 2001. P. 65. ${ }^{18}$ BENJAMIN, Walter. Origem do drama barroco alemão. Trad. Sergio Paulo Rouanet. São Paulo, Brasiliense, 1984. P. 49.
} 
idéias, em vez de ser vista como um método pouco rigoroso e eficaz, passa a ser o que temos à mão para construirmos o conhecimento das ciências humanas. Assim, é preciso assumir a impossibilidade de aprisionarmos a verdade e valorizar a representação como uma alternativa que pode ser tomada. Por isso Walter Benjamin escreve que a filosofia, para ser fiel à lei de sua forma, deve ser vislumbrada como representação da verdade, e não como guia para o conhecimento ${ }^{19}$.

Essa representação não busca o arrebatamento do leitor, como acontece com o saber. Sua prosa é sóbria e sua visão é distanciada. Sua forma de escrita deve ser completamente desvinculada de qualquer Preceito Doutrinário Imperativo. Um preceito é um conceito predeterminado e comprometido ideologicamente. A representação filosófica não trabalha com conceitos preestabelecidos como se estes dissessem o ser da verdade. "A distinção entre a verdade e a coerência do saber define a idéia como ser" 20 . E esse ser é indefinível. Portanto, a representação filosófica não pode dar ouvidos ao imperativo que visa à dogmatização do conceito. Um preceito doutrinário imperativo é qualquer conceito pronto e acabado (Abgeschlossen) que tenha a intenção (ou o “dever") de ser aplicado em uma situação particular de forma dogmática, ou seja, indiscutível. É desse tipo de conceito que a representação deve se desviar. Por isso Benjamin compreende o método como desvio (Umweg).

Diz Benjamin que "método, é caminho indireto, é desvio. A representação como desvio é portanto a característica metodológica do tratado". O desviar de Walter Benjamin também nos remete a uma quebra na continuidade. É preciso desviar-se da arrogância dos dogmas, da pretensão dos sistemas universais, enfim, de uma importante parte da tradição do pensamento humano. O desvio está na mudança de como essa fatia da tradição pensou o conhecimento. Está também na mudança de postura com relação ao conformismo de um sentido único da marcha "necessária" da humanidade no caminho de um progresso. Este progresso da humanidade, se referido ao aumento das potencialidades instrumentais do homem, que estende os membros do ser humano o possibilitando percorrer distâncias cada vez maiores em um tempo mínimo, ou seja, que o permite controlar espaço e tempo, é amplamente desenvolvido. Entretanto, no que diz

\footnotetext{
19 “Se a filosofia quiser permanecer fiel à lei de sua forma, como representação da verdade e não como guia para o conhecimento, deve-se atribuir importância ao exercício dessa forma, e não à sua antecipação, como sistema" BENJAMIN, Walter. Origem do drama barroco alemão. Trad. Sergio Paulo Rouanet. São Paulo, Brasiliense, 1984. P. 50.

${ }^{20}$ Ibidem. P. 52.
} 
respeito ao avanço da melhor convivência entre os seres humanos, esse progresso é questionável. Uma ciência que não é capaz de pensar além do instrumental, de perguntar-se sobre seus próprios fins, tem como simples objetivo a dominação da natureza. E ainda, uma ciência que acredita fazer parte dessa marcha automática rumo ao progresso técnico acaba por valorizar de maneira exagerada um modelo tecnocrático de conhecimento. Assim acontece no conceito de trabalho do social-democrata Josef Dietzgen citado por Walter Benjamin na tese 11 de Sobre o Conceito da História:

Josef Dietzgen anunciava: "O trabalho é o Redentor dos tempos modernos... No aperfeiçoamento... do trabalho reside a riqueza, que agora pode realizar o que não foi realizado por nenhum salvador". Esse conceito de trabalho, típico do marxismo vulgar, não examina a questão de como seus produtos podem beneficiar trabalhadores que deles não dispõem. Seu interesse se dirige apenas aos progressos na dominação da natureza, e não aos retrocessos na organização da sociedade 21 .

Continuando a crítica do método das ciências particulares de investigação, que rejeitam a possibilidade da representação Benjamin afirma:

\begin{abstract}
"Para que a verdade seja representada em sua unidade e em sua singularidade, a coerência dedutiva da ciência, exaustiva e sem lacunas, não é de nenhum modo necessária. E no entanto essa exaustividade sem lacunas é a única forma pela qual a lógica do sistema se relaciona com o conceito de verdade. Essa sistematicidade fechada não tem mais a ver com a verdade que qualquer outra forma de representação" ${ }^{\prime 2}$.
\end{abstract}

Se não é possível nos apropriarmos da verdade, de fato não podemos pensar que um sistema fechado de pensamento, por mais que ele seja exaustivamente perfectível, apresente (ou aprisione) a verdade em sua universalidade. Todo sistema é construído com base em saberes, e por isso, em intencionalidades, que o distanciam do ser indefinível da verdade. Assim, o autor cita a lógica, a ética e a estética - que são em suas próprias palavras "as grandes articulações que determinam não somente a estrutura dos sistemas, mas a terminologia filosófica" ${ }^{, 23}$ - como exemplo para grandes articulações que não são apenas nomes de disciplinas especializadas, mas "monumentos de uma estrutura descontínua do mundo das idéias" ${ }^{24}$. Para Benjamin essa descontinuidade é positiva. É na descontinuidade que, não seguindo um sentido linear e único, abre-se a possibilidade para a construção do novo, que independe dos saberes preestabelecidos da ideologia. A descontinuidade possibilita a criação porque ela não se fecha em si mesma,

\footnotetext{
${ }^{21}$ BENJAMIN, Walter. Sobre o Conceito da História. In: Magia, Técnica, Arte e Política: ensaios sobre literatura e história da cultura. Obras Escolhidas. Volume 1. Tradução: Sergio Paulo Rouanet. São Paulo, Brasiliense, 1985. P. 228.

22 Ibidem. P. 55.

${ }^{23}$ BENJAMIN, Walter. Origem do drama barroco alemão. Trad. Sergio Paulo Rouanet. São Paulo, Brasiliense, 1984. P. 55.

${ }^{24}$ Ibidem, p. 55.
} 
mas permite que caminhos que valorizam a autonomia em detrimento da via de mão única de uma estrutura contínua, que é pronta e terminada.

É inconcebível que algum sistema possa conter toda a verdade relacionada à ética, por exemplo, uma vez que, mesmo que ele possuísse todos os saberes enumerados pelo homem no decorrer de sua história que versassem sobre a ética, ainda restariam questões desconhecidas e/ou insolúveis pelo conhecimento. Dessa forma, o saber do homem deve ser visto em semelhança a uma estrutura descontínua, não-linear. Isso não significa dizer que é impossível estabelecer relações lógicas e coerentes entre os saberes. Afirmar esse tipo de argumento seria um contra-senso, uma vez que a estrutura da consciência humana é baseada no raciocínio lógico. O que parece ser colocado em questão é que é impossível conhecer todas as possibilidades lógicas da verdade, e que resta para nós apenas algumas conexões que fazemos com base em nossa empatia com o objeto, ou seja, com base em nossa intencionalidade. Por essa razão Benjamin afirma que "o universo do pensamento filosófico não se desenvolve pela seqüência ininterrupta de deduções conceituais, mas pela descrição do mundo das idéias" 25 .

Boris Cyrulnik, psicanalista francês, em uma conversa com o sociólogo Edgar Morin, certa vez afirmou que "o meio mais seguro de assassinar uma idéia ${ }^{26}$ é venerá-la". No texto original ele afirma:

Car Le plus Sûr moyen d'assassiner une idée, c'est de la vénérer. À force de la répéter, on la transforme en stéréotype, au point que l'on peut la réciter en pensant au dernier match France-Angleterre! Faire vivre une idée, c'est au contraire la débattre, la combattre, chercher à tuer certains éléments qui la composent. Nous savons de toutes les façons que les causalités linéaires sont abusives; c'est nous qui les fabriquons pour donner au monde une vision réductrice et donc sécurisante ${ }^{27}$.

Assim, somos nós mesmos que "produzimos" as relações entre causas e efeitos, uma vez que as identificamos com base em nossa própria experiência particular. Por isso, afirmar que uma determinada conseqüência tenha como única ou principal causa aquela que identificamos como tal, significa tender provavelmente ao erro de observar a realidade de forma reducionista. Esta é demasiado complexa para ser compreendida através de algumas poucas relações causais. As causas de um efeito podem estar séculos distantes deste. Se uma relação causal linear identificada por alguns poucos

\footnotetext{
${ }^{25}$ BENJAMIN, Walter. Origem do drama barroco alemão. Trad. Sergio Paulo Rouanet. São Paulo, Brasiliense, 1984. P. 65.

${ }^{26}$ Para evitarmos a confusão com o termo benjaminiano é importante afirmar que se deve entender a expressão "uma idéia" aqui apresentada no sentido geral de "um pensamento", ou "um conceito".

${ }^{27}$ CYRULNIK, Boris. MORIN, Edgar. Dialogue sur La nature humaine. Éditions de l'Aube, 2004. P. 45-46.
} 
pesquisadores não pode ser caracterizada sequer como universal e necessária, dado o problema imanente ao conhecimento empírico de apenas alcançar a probabilidade, muito menos se pode afirmar que determinada causa é a única ou a mais importante causa de um efeito. Como saber se não existem outras forças por hora desconhecidas que ocasionaram o efeito estudado? Assim, a realidade em sua forma de verdade mais uma vez pode ser afirmada como impossível de ser possuída pelo homem.

\section{Tratado, doutrina e sistema}

Segundo Benjamin, "o conceito de sistema, do século XIX, ignora a alternativa à forma filosófica, representada pelos conceitos da doutrina e do ensaio esotérico" ${ }^{28}$. A filosofia que é determinada pelo conceito de sistema corre o perigo de "acomodar-se num sincretismo que tenta capturar a verdade numa rede estendida entre vários tipos de conhecimento, como se a verdade voasse de fora para dentro" ${ }^{, 29}$. O problema é que o sistema fechado, acabado, planeja que a filosofia se acomode nas categorias preestabelecidas por ele, que está pronto e finalizado para receber a verdade que vem de fora. Assim como ensinam Marx e Engels na Ideologia Alemã, é inconcebível que se queira, partindo de categorias abstratas, acomodar a realidade material nessas categorias como se elas fossem uma fórmula culinária. Ao contrário, é preciso que se parta da materialidade histórica para chegarmos a categorias que estabeleçam relações efetivas com o mundo real. Sobre a essência da concepção materialista da história os autores afirmam:

\footnotetext{
Em completa oposição à filosofia alemã, a qual desce do céu à terra, aqui sobe-se da terra ao céu. Isto é, não se parte daquilo que os homens dizem, imaginam ou se representam, e também dos homens narrados, pensados, imaginados, representados, para daí se chegar aos homens de carne e osso; parte-se dos homens realmente ativos, e com base no seu processo real de vida apresenta-se também o desenvolvimento dos reflexos (Reflexe) e ecos ideológicos deste processo de vida. (...) Estas abstrações não têm, separadas da história real, o menor valor. Só podem servir para facilitar a ordenação do material histórico, para indicar a seqüência de cada um dos seus estratos. Mas não dão, de modo nenhum, como a filosofia, uma receita ou um esquema segundo o qual as épocas históricas possam ser ajeitadas ou ajustadas ${ }^{30}$.
}

Não faz sentido que se criem categorias abstratas com a intenção de que estas terão serventia universal, colhendo fenômenos e os acomodando em um falso universal da média estabelecido previamente. "O universalismo assim adquirido por essa filosofia

\footnotetext{
${ }^{28}$ BENJAMIN, Walter. Origem do drama barroco alemão. Trad. Sergio Paulo Rouanet. São Paulo, Brasiliense, 1984. P. 50.

${ }^{29}$ Ibidem, p. 50.

${ }^{30}$ MARX, Karl. ENGELS, Friedrich. A Ideologia Alemã. Tradução: Álvaro Pina. São Paulo, Editora Moraes, 1984. P.22-24.
} 
[referente ao sistema] não consegue alcançar a autoridade didática da doutrina" ${ }^{\text {31 }}$. Esse modelo de filosofia só chega ao dogmatismo que desestimula o pensamento liberto e crítico do indivíduo. O universalismo extraído da média não é capaz de vislumbrar a singularidade das diferenças. Ele visa o ensino dogmático do indivíduo, transmitindo a ele informações ideológicas, ocasionando a sua instrumentalização e a transformação do indivíduo em massa. No momento em que o homem recebe passivamente um discurso baseado em um pseudo-universal, ele se torna mera ferramenta incapaz de autoreflexão. A ideologia por ele adquirida é agora reproduzida de maneira não problematizadora.

Ainda sobre a problemática do sistema diz Benjamin que

"se a filosofia quiser permanecer fiel à lei de sua forma, como representação da verdade
e não guia para o conhecimento, deve-se atribuir importância ao exercício dessa forma,
e não à sua antecipação, como sistema" 32

O método da filosofia, baseando-se então na representação, não pode fundamentar-se no sistema. Este último é acabado e, por isso, inerte. A verdade, como foi posto anteriormente, não se apresenta de forma acabada. Esse modo não pode dar conta de sua complexidade. Segundo o autor a filosofia deve se preocupar com a representação da verdade, uma vez que quando se objetiva apoderar-se dela, tudo o que se consegue agarrar é mero conhecimento. O sistema fechado produz o sofrimento com o fim do pensamento, pois a consciência, uma vez narcotizada, reproduz as metamorfoses do mesmo. "Esse exercício [de representar a verdade] impôs-se em todas as épocas que tiveram a consciência do ser indefinível da verdade, e assumiu o aspecto de uma propedêutica. Ela pode ser designada pelo termo escolástico do tratado". 33 Pois o tratado, como diz o autor, pode ter uma aparência didática, mas não é como a doutrina que busca a transmissão de um conceito preestabelecido, sem estimular a reflexão crítica do indivíduo. Também não se utiliza do conceito de autoridade, que baseia sua veracidade na crença dogmática de que alguns mestres detinham a verdade e que seus escritos a possuíam. Para Benjamin, o tratado não tem a validade obrigatória de ser um ensino, feito para ser obedecido. Eles também não recorrem aos instrumentos coercitivos, persuasivos, passíveis de ser demonstrados. Os tratados "só contêm um

\footnotetext{
${ }^{31}$ Ibidem, p. 50.

${ }^{32}$ BENJAMIN, Walter. Origem do drama barroco alemão. Trad. Sergio Paulo Rouanet. São Paulo, Brasiliense, 1984. P. 50.

33 Ibidem, p. 50.
} 
único elemento de intenção didática, mais voltada para a educação do que para o ensinamento: a citação autorizada. A quintessência do seu método é a representação."34.

Enquanto que o verbo alemão ensinar - lehren - tem a mesma raiz de doutrina - lehre a educação é emancipadora, livre e autônoma. Ela relaciona-se com o tratado e com a proposta da representação ao mesmo tempo em que não visa a imposição de nenhuma "verdade" dogmatizada. Ela respeita as diferenças entre os indivíduos e, assumindo que nenhum pode possuir a verdade para então ensiná-la, ela estimula o pensamento autônomo da criatura. A educação se dá através da experiência de um evento, experiência esta que foi vivida pelo educando que, quando sente no corpo o acontecimento em sua materialidade, suas dificuldades e valores, ele experiencia o aprendizado, compreendendo interiormente a medida do seu valor. A educação tem a ver com a verdade que não pode ser transmitida, mas que pode ser experienciada por cada um.

O ensinamento refere-se ao ensino do dogma, do conceito fechado e inviolável. Este não respeita as diferenças de cada um, mas visa a transmissão de um conceito único e inerte para todos. Também não existe mais o indivíduo autônomo, que tem todas as possibilidades para refletir e experienciar a verdade a partir de suas próprias idiossincrasias. O ensino põe o indivíduo autômato, que ao receber o conceito de fora, deve agir como o dogmatizador padronizou que é a correta maneira de agir. É o ensino que intenciona a transmissão da ideologia.

Se o sistema relaciona-se com o ensinamento de seus pretensos universais, a educação relaciona-se com o tratado. Neste, vislumbramos a renúncia da intenção. Seu método é a representação que se desvia da intencionalidade, da ideologia. Assim como no mosaico medieval, o tratado valoriza o fragmento em sua heterogeneidade. Cada elemento do mosaico é insubstituível, porque é único em sua existência singular. Como ele não acredita dominar a verdade em todas as suas significações, o tratado é como o pensamento, que "começa sempre de novo, e volta sempre, minuciosamente, às próprias coisas" $^{\text {,35 }}$. Se não possuímos a verdade em absoluto, não podemos dar conta de todas as conexões entre os elementos que a compõem. Por isso, Benjamin propõe que tratemos da realidade como fragmentos de significação, o que respeita os abismos desconhecidos

\footnotetext{
${ }^{34}$ Ibidem, p. 50.

35 Ibidem, p. 50.
} 
situados entre as idéias. Não se pode ter a presunção de acreditar que uma disposição sistemática organizada possa deter a verdade absoluta. Assim, se dá a comparação do tratado com o mosaico. Escreve Benjamin:

Tanto o mosaico como a contemplação justapõem elementos isolados e heterogêneos, e nada manifesta com mais força o impacto transcendente, quer da imagem sagrada, quer da verdade. $\mathrm{O}$ valor desses fragmentos de pensamento é tanto maior quanto menor sua relação imediata com a concepção básica que lhes corresponde, e o brilho da representação depende desse valor da mesma forma que o brilho do mosaico depende da qualidade do esmalte. A relação entre o trabalho microscópico e a grandeza do todo plástico e intelectual demonstra que o conteúdo de verdade só pode ser captado pela mais exata das imersões nos pormenores do conteúdo material. Em sua forma mais alta, no Ocidente, o mosaico e o tratado pertencem à Idade Média. Sua comparação é possível, porque sua afinidade é real.

Os elementos heterogêneos são "justapostos”. Benjamin fala em justaposição exatamente para afirmar que não existe hierarquia entre os fragmentos do mosaico. Cada peça é insubstituível porque é única. E cada uma possui o mesmo nível de importância. Aqui não há a possibilidade da mera reposição de peças como existe no conceito de massa de Theodor Adorno. Ao vislumbrar os indivíduos como massa homogênea, pode-se inferir que cada peça padronizada pode ser substituída sem dificuldades por outra ${ }^{36}$.

\section{Indução e Dedução}

Ainda na crítica do método das ciências, Walter Benjamin discursa sobre os problemas do método indutivo e dedutivo.

Enquanto a indução degrada as idéias em conceitos, na medida em que se abstém de ordená-las e hierarquizá-las, a dedução atinge o mesmo resultado, na medida em que as projeta num continuum pseudológico. O universo do pensamento filosófico não se desenvolve pela sequência ininterrupta de deduções conceituais, mas pela descrição do mundo das idéias. Essa descrição começa sempre de novo com cada idéia, como se ela fosse primordial. Porque as idéias formam uma multiplicidade irredutível. Elas se oferecem à contemplação como uma multiplicidade que podemos enumerar, ou antes, denominar. Daí a crítica veemente de Benedetto Croce ao conceito dedutivo de gênero, adotado pela filosofia da arte. Com razão, ele vê na classificação enquanto fundamento das deduções especulativas, a origem de uma crítica superficialmente esquematizadora. $^{37}$

\footnotetext{
${ }^{36}$ Se o ponto de partida de Theodor Adorno para trabalhar a não-identidade é o semelhante, o homogêneo, o de Walter Benjamin já é o diferente, o heterogêneo. O pensador assume a existência da heterogeneidade do indivíduo, que, por mais que seja bombardeado pela indústria de massa que intenciona a venda de produtos standard, de fabricação menos onerosa através da automatização dos meios de produção em série, ele ainda resiste em suas diferenças.

${ }^{37}$ BENJAMIN, Walter. Origem do drama barroco alemão. Trad. Sergio Paulo Rouanet. São Paulo, Brasiliense, 1984. P. 65.
} 
O problema a que o autor se refere é que ambos os métodos reduzem as idéias a conceitos. O conceito é apenas média, que põe a perder toda a característica de multiplicidade de uma idéia. A indução parte da experiência para dela extrair um semelhante que terá a pretensão de dizer e englobar todas as possibilidades empíricas. Essa ação desrespeita as diferenças e as particularidades dos objetos mediatizados. A dedução, partindo de um gênero abstrato, visa incorporar este gênero médio nas espécies particulares, também ignorando e desvalorizando as suas diferenças. $\mathrm{O}$ problema das idéias se situarem em um continuum pseudológico é que, dessa maneira, a forma de ordenar as idéias foi escolhida segundo a subjetividade de um indivíduo. Essas idéias foram postas e distribuídas em um espaço com a pretensão de estarem condizentes com o ser da verdade. A questão é que das inúmeras formas em que o ser da verdade se organiza, o indivíduo apenas pode conhecer algumas maneiras limitadas. Por isso o uso do termo continuum pseudológico, traz a reflexão de que as idéias foram falsamente postas em uma ordem pretensamente racional, como se um indivíduo, a partir de seu conhecimento, tivesse as condições de posse da verdade.

Sobre a indução, Benjamin cita Scheler.

\begin{abstract}
"Como proceder? Devemos reunir todos os exemplos do trágico, isto é, todos os acontecimentos e ocorrências que transmitem aos homens a impressão do trágico, para em seguida perguntar, indutivamente, o que eles têm de comum? Seria um método indutivo, capaz de sustentação experimental. Mas isso seria ainda menos fecundo que a observação do nosso Eu, quando o trágico nos afeta. Pois com que direito podemos dar crédito à afirmação das pessoas que dizem que o trágico é aquilo que elas assim denominam?".38
\end{abstract}

Podemos inferir do comentário de Scheler três indagações acerca do método indutivo. A primeira versa sobre o caráter próprio deste método, que já foi amplamente discutido desde a formalização do método científico com os empiristas: a contingência. Não se pode chegar a uma lei necessária a partir da observação dos casos empíricos porque a conclusão que o observador infere se baseia apenas na probabilidade. Nada garante que a hipótese formada tenha existência eterna assim como não se tem garantia de que o sol nasça amanhã. Tudo que temos é probabilidade. A verdade não pode ser conhecida indutivamente.

Dito isso sobre o método indutivo, Scheler afirma em seguida que, reunidos todos os exemplos do objeto de estudo (no caso por ele apresentado, o trágico), o método ensina

\footnotetext{
${ }^{38}$ SCHELER apud BENJAMIN. BENJAMIN, Walter. Origem do drama barroco alemão. Trad. Sergio Paulo Rouanet. São Paulo, Brasiliense, 1984. P. 61.
} 
que se deve perguntar pelo semelhante que existe em cada particular. Esse processo, como já foi afirmado antes, desvaloriza justamente o que faz cada objeto ser algo diferente. Por isso, com esse processo, o conceito genérico subsume nele as diferenças que caracterizam os particulares, o que o transforma em simples média.

Mas Scheler ainda se refere a um terceiro aspecto. No caso do sentimento do trágico, sensação extremamente subjetiva, como saber se o que o pesquisador denominou de trágico é a mesma sensação que cada um dos indivíduos observados assim a denominaram? Uma vez que não é possível ter certeza de que determinada sensação experimentada por alguém é exatamente a mesma que foi sentida por uma outra pessoa, o rigor científico da investigação fica comprometido.

Como fundamentação para a discussão sobre o método dedutivo, Benjamin cita Burdach. "Prometi falar sobre a origem do Humanismo como se ele fosse um ser vivo, que veio ao mundo como um todo, em algum lugar e em algum momento, e como um todo se desenvolveu" 39 . Burdach afirma que proceder dessa maneira é proceder assim como faziam os realistas medievais, que atribuíam um caráter de realidade aos universais, ou seja, aos conceitos genéricos. Esse procedimento não faz sentido uma vez que o Humanismo, para tomarmos o exemplo utilizado, não passa de um nome criado com o fim de identificar um determinado modelo de pensamento. O humanismo é apenas um "conceito auxiliar abstrato, para podermos lidar com uma série infinita de fenômenos intelectuais e de personalidades totalmente distintas entre si” ${ }^{40}$. Esta última assertiva nos dá uma pista para a crítica da dedução. O problema é que, como já foi colocado anteriormente, objetiva-se com esse conceito auxiliar abstrato subsumir infinitas séries de fenômenos intelectuais em apenas um lugar, desrespeitando as suas diferenças e singularidades. Diz Burdach que "em consequência da nossa necessidade inata de sistematização", a partir da seleção do que nos parece um semelhante comum entre os particulares, nós acentuamos tais semelhanças muito mais do que as diferenças. Assim, chegamos ao conceito que, longe de dizer a totalidade, apenas nos apresenta uma média, uma mediocridade, o que põe a perder o conhecimento da realidade em suas formas heterogêneas de ser. Esses conceitos médios são rótulos arbitrários, e mesmo errôneos, porque atribuem a aparência ilusória de uma essência real.

\footnotetext{
${ }^{39}$ BURDACH apud BENJAMIN. BENJAMIN, Walter. Origem do drama barroco alemão. Trad. Sergio Paulo Rouanet. São Paulo, Brasiliense, 1984. P. 62.

${ }^{40}$ Ibidem, p. 62.
} 
Sobre as afirmações de Burdach, Walter Benjamin diz que

\begin{abstract}
essa posição é obviamente correta, na medida em que se dirige contra a tendência a hipostasiar conceitos gerais, embora eles não incluam os universais em todas as suas formas. Mas fracassa totalmente diante da questão de uma teoria da ciência voltada, platonicamente, para a representação das essências, pois não se dá conta de sua necessidade. Somente essa teoria pode salvar a linguagem da exposição científica, como ela funciona fora da esfera matemática, do ceticismo generalizado, que arrasta em seu abismo, no final, mesmo as metodologias indutivas mais sutis, e as formulações de Burdach são impotentes contra esse ceticismo. Porque elas constituem uma reservatio mentalis privada, e não uma garantia metodológica. Sem dúvida, no que diz respeito a tipos e épocas históricas, não podemos aceitar que idéias como a Renascença e o Barroco seriam capazes de apreender conceitualmente o seu objeto. Supor que poderíamos chegar a uma compreensão moderna dos vários períodos históricos através de confrontações polêmicas em que, como nas guinadas históricas decisivas, as épocas se enfrentam, por assim dizer, com a viseira aberta, seria desconhecer a natureza das nossas fontes, que são determinadas por interesses atuais, e não por idéias historiográficas. Mas o que esses nomes não conseguem fazer como conceitos, conseguem fazer como idéias. Pois nelas, não é o semelhante que é absorvido, e sim o extremo que chega à sua síntese ${ }^{41}$.
\end{abstract}

Walter Benjamin concorda com Burdach sobre a impossibilidade de se hipostasiar conceitos abstratos como se eles fossem uma essência real. Mas, por outro lado, o autor realça que é preciso abordar a realidade buscando a sua representação. Ao posicionarmos as palavras sob a forma de idéias - onde a partir da representação dos seus extremos as suas particularidades e singularidades são respeitadas - podemos alcançar a representação da verdade de forma satisfatória. Apenas uma teoria das ciências que objetive a representação das essências pode salvar a verdade do esforço em matematizar todas as formas do pensar. $\mathrm{O}$ modo de pensar matemático não é o único modo de conhecer. A verdade não descansa nele, o que não significa que devamos desvalorizar o saber matemático, mas pô-lo em seu devido lugar. O conhecimento é possível de inúmeras formas. As ciências humanas não obedecem fielmente ao formalismo lógico-dedutivo da matemática, ou, se obedecem, ainda não nos cabe saber; porque não possuímos conhecimento suficiente para identificar e prever com certeza um acontecimento empírico-social, como a hora de chegada de um ônibus em sua parada. Também, pôr o conhecer humano em seu lugar significa ainda não se deixar cair em um ceticismo. É preciso assumir os limites do saber para poder aproveitá-lo em suas máximas possibilidades.

O método que Benjamin propõe é assumir que esses nomes devem ser contemplados como idéias que, inatingíveis, a nós resta apenas representá-las. Esta representação não

\footnotetext{
${ }^{41}$ BENJAMIN, Walter. Origem do drama barroco alemão. Trad. Sergio Paulo Rouanet. São Paulo, Brasiliense, 1984. P. 63.
} 
objetiva isolar o elemento semelhante, mas respeitar as diferenças extraindo os extremos presentes na idéia.

\section{Alegoria e Símbolo}

Aceitar a linguagem como o fundamento literal de um conceito é um problema para Benjamin porque, quando delimitamos muito fortemente um conceito a um significado fixo, corremos o risco de subsumir nele multiplicidades de significados que enriqueciam um pensamento. Isso nos leva à discussão sobre a alegoria. Ao contrário do símbolo, que cristaliza o sentido, a alegoria apresenta uma pluralidade de significações.

O termo alegoria, segundo Sergio Paulo Rouanet afirma na apresentação de sua tradução brasileira de Origem do Drama Barroco Alemão, deriva etimologicamente de allos, outro, e agoreuein, falar na ágora. Dessa forma, em uma linguagem literal, falar alegoricamente significa dizer uma coisa para significar outra. A alegoria possui uma significação plurívoca, onde o outro dito por ela não transparece, não se mostra de forma explícita. Ela constitui o jogo entre o desvelar e o encobrir. É uma figura própria para o nosso tempo de indefinição e de uma complexidade de referenciais. Dessa forma ela se insurge contra o símbolo, contra o significado unívoco e fossilizado pela convenção. No símbolo, não há a tentativa de dizer o outro, mas de dizer exatamente o que o símbolo mesmo significa, o que caracteriza a oposição à alegoria. O significado do símbolo é transparente, evidente. Ao buscar interpretá-lo, obtém-se a certeza de sua significação. Para que esta certeza se manifestasse, foi preciso fixar no símbolo uma convenção, um sentido arbitrário, intencional. O crucifixo simboliza Jesus Cristo, o cordeiro de Deus imolado, a fim de realizar a remissão dos pecados. Essa interpretação do crucifixo não abre espaço para muitas interpretações facilmente. Convencionou-se que aquele objeto, ou melhor, aquela imagem representaria o sacrifício do Deus feito carne em favor de seus filhos. Certamente, pode-se buscar por significados alegóricos dentro deste signo, mas seu sentido principal, que terá sempre a maior prioridade de leitura, permanecerá. Na interpretação alegórica não há um significado óbvio. Devido a sua abertura, sua potencialidade interpretativa, ela deixa espaço para o leitor refletir a partir de suas próprias experiências. A coerência da teoria do alegórico com a crítica do conhecimento mostra-se clara. Se ninguém pode deter o direito de possuir a verdade, a alegoria louva essa linha de pensamento quando respeita e valoriza as diferenças de cada indivíduo. Essa é a relação possível entre alegoria e verdade. 
Se a alegoria comporta uma multiplicidade de significados, fica posto que a alegoria se afasta da esfera da intenção. Isso acontece porque como não há um manual para a leitura da alegoria, que ensine ${ }^{42}$ como se deve significá-la, fica aberto para cada um que perceber a imagem, significá-la a seu modo singular. É essa orientação que podemos encontrar no texto $O$ Narrador, de 1936, quando Benjamin diz que

metade da arte narrativa está em evitar explicações. Nisso Leskov é magistral (...). O extraordinário e o miraculoso são narrados com a maior exatidão, mas o contexto psicológico da ação não é imposto ao leitor. Ele é livre para interpretar a história como quiser, e com isso o episódio narrado atinge uma amplitude que não existe na informação ${ }^{43}$.

Com o conceito estabelecido e pronto, corremos o risco de colocá-lo no plano do dogma. Este trabalha com o pensar preestabelecido, imóvel e inerte. Parece ser esse o problema de buscar alcançar a verdade com a coerência do método da ciência exaustiva e sem lacunas. O dogma não valoriza a representação de verdade nas suas múltiplas significações. Ele se baseia no conceito de autoridade, onde um texto possui um valor extrínseco que o faz parecer sempre verdadeiro, independente de seu conteúdo. Essa forma de lidar com o texto se aproxima muito mais da religião do que da filosofia. Os textos ganham uma característica de sacralidade incontestável.

\section{Representar as idéias, salvar os fenômenos}

Os conceitos não podem coincidir com a verdade. Seu papel é mediador. "Os fenômenos não entram integralmente no reino das idéias em sua existência bruta, empírica, e parcialmente ilusória, mas apenas em seus elementos, que se salvam ${ }^{44 \text { ". São }}$ os conceitos que fazem a mediação entre os fenômenos e as idéias, permitindo que os primeiros participem do ser das idéias. Os conceitos “dissolvem as coisas em seus elementos constitutivos ${ }^{45}$ ". Por essa tarefa mediadora, que relaciona os fenômenos com as idéias, eles também executam uma outra tarefa: a representação dessas idéias.

A redenção dos fenômenos por meio das idéias se efetua ao mesmo tempo que a representação das idéias por meio da empiria. Pois elas não se representam em si

\footnotetext{
${ }^{42} \mathrm{O}$ verbo ensinar aqui segue a orientação benjaminiana explicada anteriormente.

${ }^{43}$ BENJAMIN, Walter. O narrador: considerações sobre a obra de Nikolai Leskov. In: Magia, Técnica, Arte e Política: ensaios sobre literatura e história da cultura. Obras Escolhidas. Volume 1. Tradução: Sergio Paulo Rouanet. São Paulo, Brasiliense, 1985. P. 228.

44 BENJAMIN, Walter. Origem do drama barroco alemão. Trad. Sergio Paulo Rouanet. São Paulo, Brasiliense, 1984. P. 55-56.

${ }^{45}$ BENJAMIN, Walter. Origem do drama barroco alemão. Trad. Sergio Paulo Rouanet. São Paulo, Brasiliense, 1984. P. 56.
} 
mesmas, mas unicamente através de um ordenamento de elementos materiais no conceito, de uma configuração desses elementos ${ }^{46}$.

Dessa forma, são possíveis para o conceito, duas funções: salvar os fenômenos e representar as idéias. Salvar os fenômenos porque os conceitos os reconhecem e os ordenam. Representar as idéias porque os conceitos agrupando os fenômenos, podem descrever as idéias. Digo descrição porque os fenômenos não estão contidos nas idéias. Estas apenas são a interpretação objetiva dos fenômenos, "seu ordenamento objetivo virtual $^{47}$ ". "O conjunto de conceitos utilizados para representar uma idéia atualiza essa idéia como configuração daqueles conceitos" ${ }^{\text {"48 }}$. Isso ocorre porque não podemos conhecer as idéias como elas são em si mesmas, mas apenas suas representações.

Os fenômenos determinam o fim e o conteúdo dos conceitos. Já as idéias, uma vez que são a interpretação objetiva dos fenômenos, "determinam as relações de afinidade mútua entre tais fenômenos",49, ou seja, lhes dão significado objetivo. "A verdade é uma essência não-intencional formada por idéias". As idéias, diferentemente dos conceitos que se relacionam com o saber, coincidem com a verdade. "A idéia é algo de lingüístico, é o elemento simbólico presente na essência da palavra"50. Para Benjamin, a linguagem, no momento de sua origem, quando despida de qualquer intenção, possui um conteúdo de verdade. "A tarefa do filósofo é restaurar em sua primazia, pela representação, o caráter simbólico da palavra, no qual a idéia chega à consciência de si, o que é o oposto de qualquer comunicação dirigida para o exterior" ${ }^{, 51}$. Cabe aos conceitos representar as idéias para se aproximar dessa interpretação objetiva.

\footnotetext{
Uma ciência que protesta contra a linguagem de suas investigações é absurda. Juntamente com os signos da matemática, as palavras são os únicos instrumentos de representação da ciência, e elas próprias não são signos. Pois no conceito, ao qual obviamente corresponderia o signo, a própria palavra que realiza sua essência como idéia se despotencializa ${ }^{52}$.
}

Sergio Paulo Rouanet, na apresentação de sua tradução da obra de Benjamin, afirma que “a verdade está na dimensão nomeadora da linguagem”. Assim, Benjamin nos diz que é preciso retornar à linguagem adamítica que se situava antes do pecado original. Essa linguagem, desprovida de intenção, teria a capacidade de dizer o conteúdo da verdade.

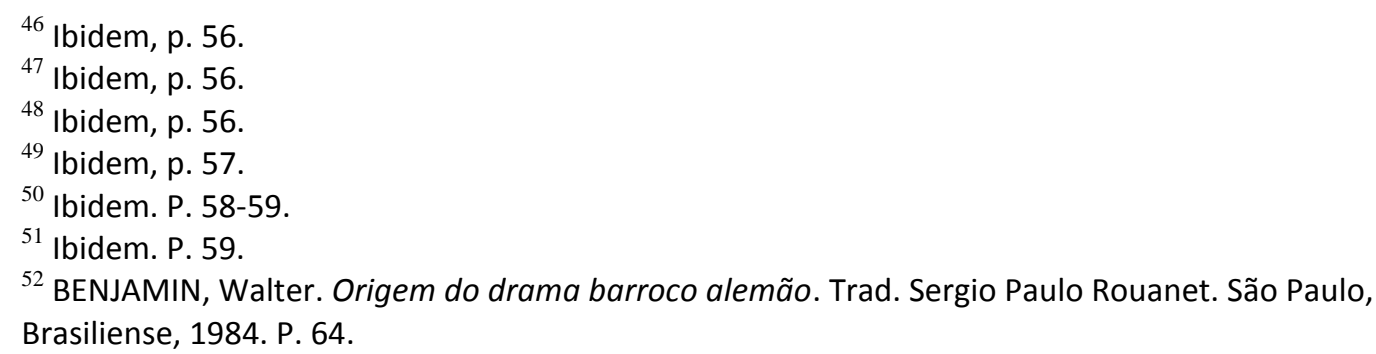


O autor propõe o conceito de anamnesis no sentido de que é preciso, na reminiscência desse passado atemporal, buscar o elemento simbólico puro da palavra. Este ato é tarefa do filósofo. A nomeação adamítica não é arbitrária.

A nomeação adamítica está tão longe de ser jogo e arbítrio, que somente nela se confirma a condição paradisíaca, que não precisava ainda lutar contra a dimensão significativa das palavras. As idéias se dão, de forma não-intencional, no ato nomeador, e têm de ser renovadas pela contemplação filosófica. Nessa renovação, a percepção original das palavras é restaurada ${ }^{53}$.

Nesse sentido, Benjamin nos fala que toda a filosofia tem sido "uma luta pela representação de algumas poucas palavras, sempre as mesmas - as idéias" ${ }^{\text {"54 }}$. Quando tentamos introduzir novas terminologias não provenientes do tempo paradisíaco, estas não podem possuir verdadeira objetividade. Pois nessas novas terminologias, "a intenção possui maior peso que a linguagem".

\section{Eros e a revelação da verdade}

Para o autor, existe um momento especial em que é possível, em um lampejo de revelação, vislumbrar a verdade. Este momento se dará com a contemplação da verdadeira obra de arte. Quando os seus conteúdos factuais de valor histórico desaparecem, isto é, no momento em que a obra de arte se transforma em ruína, sofrendo uma descontextualização de seu espaço original, a obra de arte pode se apresentar isenta da intencionalidade que lhe foi atribuída no momento de sua confecção. Assim, o revelar-se da verdade na obra de arte corresponde exatamente à eliminação de toda e qualquer intenção, é um revelar-se inconsciente. Benjamin atribui à obra de arte o valor de uma historiografia inconsciente. Não podemos nos apropriar do segredo da verdade, mas deixar que ela se auto-apresente em seu revelar. É na fugidia imagem dialética - dialektik imstillstand - que se dá o aparecimento da verdade. Tal qual um relâmpago, ela aparece como fulguração, em um instante que não se paralisa, impedindo que nós a possuamos.

\footnotetext{
A beleza, em geral, permanecerá fulgurante e palpável enquanto admitir francamente ser uma simples fulguração. Seu brilho, que seduz, desde que não queira ser mais que brilho, provoca a inteligência que a persegue, e só quando se refugia no altar da verdade revela sua inocência. Amante, e não perseguidor, Eros a segue em sua fuga, que não terá fim, porque a beleza, para manter a sua fulguração, foge da inteligência por terror e, por medo, do amante. E somente este pode testemunhar que a verdade não é desnudamento, que aniquila o segredo, mas revelação, que lhe faz justiça".
}

\footnotetext{
53 Ibidem, p. 59.

54 Ibidem, p. 59.
} 
A representação das idéias está longe de aniquilar o inalcançável segredo da verdade. É uma força que se renova constantemente. Ela não pode ser desnudada pela inteligência que a persegue, ou seja, pelo saber. A consciência do homem precisa assumir a tarefa da representação e esquecer o desejo vaidoso de aprisionar o ser da verdade na média. E esperar que a verdade relampeje e se revele espontaneamente àquele que a contemple em uma iluminação profana. É preciso tomar o objeto como uma idéia representada. Nesse processo, o invólucro, ou seja, a casca impregnada de ideologia pode ser destruída revelando a verdade que esteve por debaixo das aparências.

\section{Considerações Finais}

As ideias pertencem a quem as compreende. Apesar de ter lido esse dito quando era criança, nunca o esqueci. Retornava a mim sempre que a situação convinha. Quem foi seu autor, não me lembro, embora se compreendermos o que diz a máxima, conhecer sua autoria se torna sem importância. Na leitura de Benjamin, constantemente me recordei dessa frase, recipiente de um conteúdo tão complicadamente simples: a verdade não tem dono.

O saber, em contrapartida, o tem. Há saberes, entretanto, que de tão interiores à cultura de um povo, pertencem à coletividade. Se existe uma universalidade no saber, seria esse o caminho possível: compreender o universal como o conhecimento coletivo de um saber arraigado e generalizado no modo de ser do homem. Benjamin se reporta a esse saber ao falar da citação autorizada, princípio encontrado no tratado medieval que nos traz a reflexão de que existem saberes tão essenciais e difundidos que não é possível definir sua autoria. Um saber que expressa o inconsciente de uma cultura não pode ter apenas um autor, mas vários: todos que um dia já compreenderam a intensidade do seu conteúdo.

\section{REFERÊNCIAS}

BENJAMIN, Walter, Origem do Drama Barroco Alemão (Trad. Sérgio Paulo

Rouanet), São Paulo: Brasiliense, 1984. Magia e Técnica, Arte e Política- Obras Escolhidas I 
(Trad.Sérgio Paulo Rouanet, São Paulo: Brasiliense, 1985. 